\title{
VIVÊNCIAS EMOCIONAIS E ESTRATÉGIAS DE REGULAÇÃO EMOCIONAL DE PSICÓlOGOS CLÍNICOS: UM ESTUDO QUALITATIVO
}

\author{
Marina da Silva de Matos \\ Escola Superior de Criciúma - Esucri
}

Sílvia Batista Von Borowski

Escola Superior de Criciúma - Esucri

\begin{abstract}
Resumo
A regulação emocional em intervenções psicoterapêuticas pode ser eficaz para lidar com situações, como o desconforto, não permitindo que o estado emocional afete a qualidade dos atendimentos. O intuito deste estudo é abordar o estado emocional dos psicoterapeutas em situações intensas do trabalho clínico. Para isso, recorreu-se à pesquisa de cunho descritivo e exploratório, em dados qualitativos. Foram realizadas cinco entrevistas, seguindo um roteiro de entrevistas semiestruturadas com perguntas abertas. Na sequência, o material foi transcrito e submetido à análise de conteúdo de Bardin (1977). Apesar de a regulação emocional fazer parte da rotina dos entrevistados, o uso das estratégias advém das experiências do cotidiano e, em menor proporção, das aprendizagens de formação. Considera-se que ampliar a compreensão do impacto da regulação emocional na prática clínica é necessário para a criação de estratégias de enfrentamento que cuidem da saúde mental do psicoterapeuta e do usuário do serviço.
\end{abstract}

Palavras-chave: psicoterapia; psicoterapeuta; regulação emocional.

\section{EMOTIONAL EXPERIENCES AND EMOTIONAL REGULATION STRATEGIES OF CLINICAL PSYCHOLOGISTS: A QUALITATIVE STUDY}

\begin{abstract}
The Emotional regulation in psychotherapeutic interventions can be effective in dealing with situations such as discomfort, not allowing the emotional status to affect the quality of care. The intention of this study is to address the emotional status of the psychotherapists in intense clinical work situations. To do so, we use a research of descriptive and exploratory nature, in qualitative data. Five interviews were conducted, following a script of semi-structured interviews with open questions. Consequently, the material was transcribed and subjected to the content analysis of Bardin (1977). Although emotional regulation is part of the routine of interviewees, the use of strategies comes from everyday experiences and, in a smaller scale, from learning experiences. It is considered that broadening the understanding of the impact of emotional regulation in clinical practice is necessary for the creation of confrontation strategies that take care of the mental health of the psychotherapist and the service user.
\end{abstract}

Keywords: psychotherapy; psychotherapist; emotional regulation. 


\title{
VIVENCIAS EMOCIONALES Y ESTRATEGIAS DE REGULACIÓN EMOCIONAL DE PSICÓLOGOS CLÍNICOS: UN ESTUDIO CUALITATIVO
}

\begin{abstract}
Resumen
La regulación emocional en intervenciones psicoterapéuticas puede ser eficaz para lidiar con situaciones como la incomodidad, no permitiendo que el estado emocional afecte la calidad de las atenciones. La intención de este estudio es abordar el estado emocional de los psicoterapeutas en situaciones intensas del trabajo clínico. Para ello, se recurrió a la investigación de naturaleza descriptiva y exploratoria, en datos cualitativos. Se realizaron cinco entrevistas, siguiendo un guión de entrevistas semiestructuradas con preguntas abiertas. En consecuencia, el material fue transcrito y sometido al análisis de contenido de Bardin (1977). A pesar de que la regulación emocional forma parte de la rutina de los entrevistados, el uso de las estrategias proviene de las experiencias de lo cotidiano y, en menor proporción, de los aprendizajes de formación. Se considera que ampliar la comprensión del impacto de la regulación emocional en la práctica clínica es necesario para la creación de estrategias de enfrentamiento que cuidan la salud mental del psicoterapeuta y del usuario del servicio.
\end{abstract}

Palabras clave: psicoterapia; psicoterapeuta; regulación emocional.

\section{INTRODUÇÃO}

O estado emocional tem um papel fundamental no comportamento do sujeito, no que diz respeito a satisfazer suas necessidades ou a evitar situações que podem gerar o desconforto. Para Soto (2002), a função da emoção é proporcionar ao organismo o nível de excitação adequado segundo a emissão da resposta mais idônea a cada situação específica. A emoção forma um elo importante no comportamento humano e tem papel valoroso no processo motivacional.

A emoção é uma condição complexa e momentânea que surge de experiências afetivas, ocasionando alterações nas áreas dos funcionamentos psicológico e fisiológico, as quais preparam o sujeito para a ação (Miguel, 2015). É por meio dos estímulos de excitação que o organismo processa as respostas emocionais, no que se refere aos comportamentos externos. Wittig (1981) menciona que o corpo libera uma série de comportamentos e reações fisiológicas no período em que o sujeito encontra-se emocionado. Podem ocorrer reações como: afetos subjetivos (impressão subjetiva); mudanças corporais (alterações fisiológicas) como sudorese; dilatação nas pupilas; alteração dos batimentos cardíacos e da respiração; reações comportamentais como expressões faciais e vocais; alterações na postura ou mesmo dos movimentos (Miguel, 2015).

As emoções correspondem a uma reação psicológica complexa e estão ligadas diretamente à inteligência, à motivação e ao impulso que o sujeito leva para a ação. Com a interação do meio social e da personalidade do sujeito, resultam em alterações fisiológicas do organismo e que direcionam o bem-estar subjetivo. Por meio das interações sociais, as emoções podem alimentar as funções relativas à comunicação e à sociabilidade, interligação que sustenta as informações dos pensamentos e as intenções do outro. A interação social positiva 
é fundamental para que os sujeitos manejem as informações emocionais de forma inteligente e saudável (Woyciekoski \& Hutz, 2008).

A regulação emocional é essencial para o controle das expressões emocionais, comportamentais e fisiológicas do sujeito, sendo uma característica pessoal e profissional importante para a atuação dos psicólogos clínicos. Leahy, Tirch e Napolitano (2013) abordam que a regulação emocional é uma estratégia de enfrentamento pessoal, que o sujeito utiliza para lidar com a intensidade emocional experimentada. A regulação emocional é entendida como uma habilidade importante de interação social que influencia nos comportamentos e nas expressões emocionais. Cada emoção requer diferentes estratégias de regulação ou de enfrentamento, com a finalidade de lidar melhor com as situações estressantes do cotidiano. Naturalmente, a presença de emoções intensas, e muitas vezes, negativas, exige uma adaptação do organismo, no sentido de o sujeito empregar estratégias de enfrentamento ou de regulação emocional para que obtenha o equilíbrio emocional e adquira o bem-estar físico e psíquico (Cruvinel \& Boruchovitch, 2010).

Segundo Rodrigues e Gondim (2014), o processo de regulação emocional consiste em manejar as emoções para melhor se adaptar ao contexto em que o sujeito se encontra. Esse processo possibilita modular a emoção quanto ao tempo de duração, à magnitude e à latência. Suas funções envolvem defender o sujeito de situações indesejáveis, a fim de evitar os sofrimentos, com o intuito de preservar o seu bem-estar. A regulação emocional é essencial para a adaptação do sujeito ao meio. Todos os contextos exigem que o sujeito crie um repertório de respostas emocionais compatíveis e/ou socialmente adequadas ao ambiente. Portanto, no trabalho e entre as relações sociais ali estabelecidas, a aplicabilidade dessas respostas exige compreensão e educação emocional. 0 desenvolvimento de estudos sobre estratégias emocionais no contexto de trabalho é de grande relevância. Rodrigues e Gondim (2014) desenvolveram um estudo quantitativo sobre as relações entre emoções e estratégias de regulação emocional de 400 servidores públicos em suas relações de trabalho cotidianas. Destaca-se, dentre os resultados desse estudo, segundo os autores, a significativa frequência da manifestação da raiva, da emoção associada ao descontentamento com o trabalho executado. Além disso, o grupo investigado fazia uso da regulação profunda, método em que se antecipam as respostas ao ambiente e às situações.

A profissão de psicologia exige de seus profissionais habilidades e competências específicas para lidar com o sofrimento alheio. A formação desse profissional está alicerçada na ideia de preparo emocional e psíquico para lidar com demandas pessoais e laborais. No entanto, isso nem sempre ocorre, o que pode impactar na maneira como cada profissional lida com os conteúdos emergidos em clínica ou nos contextos de trabalho. A inteligência emocional consiste em uma característica essencial no desempenho do trabalho, para o 
psicólogo ou para qualquer outro profissional de área diversa (Cobêro, Primi, \& Muniz, 2006).

É possível obter a regulação emocional por intermédio de algumas estratégias, como: seleção da situação, atenção posicionada e mudança cognitiva, que podem auxiliar no controle de resposta manifesta. A seleção da situação é uma estratégia comportamental que consiste em escolher situações diante de um cenário com inúmeras alternativas, a fim de evitar emoções desagradáveis para o sujeito. A atenção posicionada é uma estratégia de mudança no foco de atenção da emoção, sob a forma de distração, ruminação e concentração. A mudança dos pensamentos é a tentativa de alterar o significado da emoção, modificando a forma como se pensa sobre determinada situação ou a capacidade de gerenciar as demandas advindas dela (Rodrigues \& Gondim, 2014). As interpretações da cognição são um reflexo do histórico de vidas, das experiências individuais e sociais, e a forma que os sujeitos enxergam o mundo. (Miguel, 2015).

Rodrigues e Gondim (2014) asseveram que a utilização da estratégia de regulação superficial ocorre após o sujeito ter sido surpreendido pela emoção, de maneira que esse precisa modular os seus estados fisiológicos e suas expressões emocionais para se manter emocionalmente equilibrado. Essa regulação é feita pelo controle das reações fisiológicas do corpo. Por meio da utilização de exercícios de respiração e de relaxamento, obtém-se o bem-estar. Esses exercícios podem contribuir no bem-estar e na regulação emocional de psicoterapeutas.

As emoções são entendidas por diferenças individuais e apontam que 0 jeito que os sujeitos gerenciam os eventos estressantes seja essencial para a determinação do seu bem-estar subjetivo. Os traços afetivos, os níveis de ansiedade, tendências pró-sociais e o perfil de assimetria da ativação hemisférica cerebral tende a influenciar a habilidade de regular as emoções (Mocaiber et al., 2008).

As emoções negativas favorecem as ações que compõem a emoção: fugir, atacar, esquivar-se e recolher-se. As emoções negativas têm efeitos tóxicos para - corpo, mas são necessárias para o desenvolvimento biopsicossocial dos psicoterapeutas no trabalho da clínica. Quando as emoções passam a ser frequentes e intensas, essas cadeias de respostas fisiológicas podem vir a prejudicar a saúde de uma pessoa (Silvestre $\&$ Vandenberghe, 2013). Silvestre e Vandenberghe (2013) complementam que a tendência das emoções positivas é estarem ligadas a ações mais amplas e difusas, enquanto que as negativas são mais específicas.

Um dos trabalhos dos psicólogos é intervir diretamente com o sofrimento das pessoas. $O$ fato de lidar constantemente com a dor das pessoas pode gerar 0 sofrimento em psicólogos clínicos devido ao conteúdo de trabalho. De acordo com a afirmação de Silva e Merlo (2007), o sofrimento psíquico é o estudo da 
psicopatologia do trabalho e implica um estado de luta do sujeito contra as forças que o empurram em direção à doença mental.

Embora os psicólogos cuidem da saúde mental de seus pacientes, muitos estão adoecendo em decorrência da profissão. O conjunto de variáveis como carga de trabalho excessiva, número de pessoas a quem os psicólogos fornecem seus serviços, o tempo de experiência e os tipos de emprego podem interferir na saúde emocional desses (Rodriguez \& Carlotto, 2017). Tais condições são influenciadas pelas demandas emocionais intensas decorrentes do fato de estar em constante contato com o sofrimento das pessoas.

As novas oportunidades profissionais de trabalho no campo da psicologia causam o aumento do estresse ocupacional e da complexidade do grau do trabalho, gerando o adoecimento dos psicólogos. O número de pacientes que o psicoterapeuta atende por dia, assim como os desgastes físico e emocional ocasionados pelos atendimentos, são causas de cansaço, das dores de cabeça, sonolência, mal-estar, entre outros sintomas (Rodriguez \& Carlotto, 2017). Em relação ao estresse no ambiente de trabalho, os autores afirmam que:

Uma característica das pessoas com inteligência emocional mais desenvolvida seria a capacidade de perceber e avaliar seus estados emocionais com maior precisão, com vistas a expressar seus sentimentos nos momentos adequados e a regular seu humor de maneira eficaz. Dessa maneira, seriam capazes de utilizar estratégias de enfrentamento do estresse de maneira mais adequada. A dificuldade em processar e regular a própria experiência emocional seria um dos fatores que causam o enfrentamento mal adaptativo. Portanto, em ambientes muito exigentes ou desafiadores, a influência da inteligência emocional deveria se dar por meio da seleção e controle de estratégias e competências que visariam ao enfrentamento da situação imediata, levando em consideração o domínio das emoções (Miguel \& Noronha, 2009, p. 219).

Logo, os psicólogos se baseiam em seus conhecimentos, moldados pelas experiências de vida, personalidade, temperamento, biologia e espiritualidade. Essas características podem contribuir como pontos fortes de vulnerabilidade. American Phychological Association [APA] (1996), os psicólogos entram na profissão por questões pessoais e utilizam as próprias respostas emocionais e cognitivas como ferramentas de trabalho na clínica. O psicólogo busca criar empatia e identificação com o tipo de paciente.

A vida acontece para o psicólogo como para qualquer pessoa. Ao longo da carreira profissional, pode enfrentar, em sua vida particular, doenças, fome, experiências traumáticas, casamentos, divórcios, nascimento ou adoção de crianças, tragédias familiares e triunfos. Cada um desses eventos afetará o psicólogo no trabalho, como pode afetar qualquer pessoa na sociedade. Popularmente, os psicólogos são vistos como uma pessoa detentora do poder para o não adoecimento mental. Alguns relatos de clientes podem rememorar eventos dolorosos como perdas, traumas, desespero, brutalidade, terror e/ou 
tragédias. Esses relatos podem estar intimamente relacionados à vida do psicoterapeuta (APA, 1996).

A atuação dos psicólogos clínicos tem um papel fundamental para a saúde. A adoção de um conceito de saúde mais amplo contribuiu para a construção de instrumentos para avaliar o bem-estar subjetivo, a qualidade de vida e as habilidades sociais. O psicólogo desenvolve um referencial teórico para auxiliar no diagnóstico de problemas e propor intervenções mais efetivas, embasado nos seus conhecimentos e pesquisas sobre eficácia e eficiência de seus métodos (APA, 1996).

A prática profissional do psicólogo é direcionada para a necessidade de ajuda psicológica para lidar com determinadas situações pessoais, as quais alguns indivíduos não conseguem resolver sozinhos. É importante que os psicólogos busquem se conhecer melhor para conseguir compreender os seus pacientes. Promover o autoconhecimento e aumentar a capacidade de organização interna das próprias emoções refletem significativamente em sua própria saúde mental e, também, na qualidade do serviço fornecido à comunidade (APA, 1996). A gerência das próprias emoções influencia nas particularidades do contexto de trabalho, contribuindo para a qualidade dos serviços prestados aos pacientes.

Para Machado et al. (2008), os mecanismos de autorregulação envolvem competências cognitivas, emocionais e sociais, e, sobretudo, envolvem as amizades e as interações sociais. Os três componentes da competência emocional estão associados ao conhecimento das emoções, à regulação das emoções e à expressão emocional em situações sociais.

A competência social está alicerçada na crença da possibilidade de produzir mudanças na sociedade, a partir de uma atitude competente em cada espaço profissional. A importância de desenvolver psicólogos mais competentes socialmente e mais profissionalmente empenhados em promover mudanças de vida nas pessoas e nas suas famílias (Lima \& Cerveny, 2012). Essas crenças podem estar presentes em vários pacientes.

A regulação emocional é a inversão da regulação. Logo, Leahy et al. (2013) destacam que a desregulação emocional é a dificuldade de lidar com experiências problemáticas ou de processar as emoções. A desregulação pode ser manifestada no sujeito tanto com a intensificação excessiva como com a diminuição excessiva das emoções. A intensificação das emoções resulta em pânico, terror, trauma, temor ou senso de urgência, no qual o sujeito se sente sobrecarregado e com dificuldades de tolerar certas emoções. A diminuição das emoções impede o processamento emocional e está caracterizada como um estilo de enfrentamento, a esquiva. A importância do psicoterapeuta consiste em atingir o controle da emoção como uma estratégia adaptativa e de enfrentamento pessoal para lidar com situações desafiadoras. 
Apesar disso, a gerência emocional, por parte dos psicólogos pode ser um problema quando se trata de experiências que marcaram a vida do paciente e que são trazidas na psicoterapia. Aquela experiência marcante e até mesmo traumatizante é a mesma situação vivenciada pelo psicoterapeuta em sua vida. Contudo, compreender esses fenômenos que ocorrem em ambientes clínicos é fundamental para desenvolver as competências pessoais, profissionais, emocionais e sociais dos psicólogos clínicos, com o intuito de promover atendimentos psicoterapêuticos mais eficazes.

Pretende-se apresentar os resultados de uma pesquisa de cunho qualitativo realizada no ano de 2017, com cinco psicólogas clínicas da abordagem terapia cognitivo-comportamental na região Sul de Santa Catarina, atuantes na área há mais de dois anos. Como objetivo, conhecer suas vivências e as estratégias de regulação emocional advindas do cotidiano de trabalho em psicoterapia.

\section{MÉTODO}

Foi realizada uma pesquisa de campo, de cunho qualitativo, de natureza aplicada, classificada como descritiva e exploratória. Segundo Strauss e Corbin (2008), a pesquisa qualitativa busca garantir ao entrevistado a flexibilidade e a liberdade para explorar os fenômenos em sua profundidade. Para Gil (2002), a pesquisa exploratória vai alavancar o desenvolvimento de ideias acerca do estudo, enquanto que o aspecto descritivo se presta a caracterizar o fenômeno.

O projeto foi aprovado pelo Comitê de Ética em Pesquisa com Seres Humanos com o registro CN (No 084842/2017), da Escola Superior de CriciúmaESUCRI. A pesquisa de campo foi realizada nos meses de setembro a novembro de 2017.

Para a realização da pesquisa, foi utilizado um roteiro de entrevistas com perguntas abertas. Para Creswell (2010), na entrevista de cunho qualitativo, o pesquisador é responsável por conduzir as entrevistas, estando frente a frente com as pessoas. A entrevista semiestruturada almejou dar a liberdade de o entrevistado se expressar, sem ter um roteiro pronto de perguntas e respostas, deixando a pessoa livre para discorrer sobre o assunto na sua singularidade. Todas as entrevistas foram gravadas com a autorização dos participantes, por meio de um termo de consentimento livre e esclarecido.

A amostragem foi composta a partir da técnica de bola de neve, na qual cada participante da entrevista encaminha outro contato para a participação, de acordo com a disponibilidade e a aceitação do sujeito em participar da entrevista. Conforme Vinuto (2014, p.3) "o tipo de amostragem nomeado como bola de neve é uma forma de amostra não probabilística, que utiliza cadeias de referência". A coleta de dados foi presencial, optando-se por realizá-la no espaço 
clínico do participante. A pesquisa de campo foi realizada no período de julho a novembro de 2017.

Foi realizada uma análise de conteúdo de Bardin (1977), com a finalidade de descrever e compreender os fenômenos relacionados ao ambiente de trabalho clínico de psicoterapeutas, quanto a maneira como gerenciam suas emoções positivas e negativas. A categorização foi a priori a partir das perguntas do roteiro, no qual é fornecido o sistema de categorias e repartem-se os elementos de acordo com a fala dos participantes, por meio do referencial teórico. Para Campos e Turato (2009), a análise de conteúdo é um conjunto de estratégias, cujo objetivo é a busca dos sentidos contidos sob os documentos, material coletado por meio das entrevistas. A estratégia de análise de conteúdo "não está na quantificação, mas na análise do fenômeno em profundidade, elencando a subjetividade, suas relações, bem como as interlocuções na malha social" (Cavalcante, Calixto, \& Pinheiro, 2014, p.5).

\section{Participantes}

Participaram da pesquisa cinco psicólogos clínicos, sendo um do sexo masculino e quatro do sexo feminino, atuantes em duas cidades de médio porte em Santa Catarina. A faixa etária variou de 25 a 36 anos de idade. 0 tempo de atuação na área clínica variou de 2 a 11 anos de profissão, tendo por critério de inclusão na pesquisa a atuação na área clínica há mais de 2 anos, na abordagem Terapia Cognitivo-Comportamental e, obrigatoriamente, ativos no Conselho Regional de Psicologia - CRP12.

Os nomes dos participantes investigados foram substituídos por nomes de flores brasileiras para preservar a imagem desses e como uma forma de gratificação pela participação na pesquisa. Os participantes receberam os nomes de Violeteira, Alamanda, Amarílis, Bromélia e Dália.

\section{Instrumentos}

Foi usado um roteiro de entrevistas semiestruturadas com perguntas sobre o perfil dos entrevistados e perguntas abertas sobre o tema de pesquisa, para assim caracterizar os voluntários. No conteúdo do roteiro, continha o perfil do participante, a lei e os direitos do mesmo e as quatro perguntas a seguir: 1) Qual a importância do controle emocional, enquanto psicoterapeuta? 2) De que forma gerencia suas emoções positivas (amor, alegria, euforia) e negativas (dor, raiva, tristeza) no âmbito clínico? 3) Já vivenciou alguma situação em que você precisou controlar o seu estado emocional no ambiente clínico? Como procedeu? Utilizou alguma técnica? 4) Em algum momento você perdeu o controle emocional quando o cliente/paciente, trouxe uma situação pessoal traumatizante? Relate como conseguiu manejar a situação em psicoterapia. 


\section{Procedimentos}

A pesquisa não precisou solicitar a autorização institucional pelo fato de os psicólogos clínicos atuarem de forma autônoma. Os psicólogos foram convidados a participar da pesquisa e, após a sua autorização, as pesquisadoras deslocaramse para os consultórios clínicos particulares de cada voluntário. Todos os participantes assinaram o Termo de Consentimento Livre e Esclarecido. Todas as entrevistas foram gravadas com a autorização dos participantes. As perguntas do roteiro foram lidas individualmente, dando a liberdade ao participante de responder com tranquilidade e com o tempo que julgasse necessário.

Considerando o processo de análise de conteúdo, o conjunto dos relatos apontou vivências relacionadas ao ambiente clínico e à forma de lidar com as adversidades. São descritas, a seguir, as estratégias de enfrentamento pessoal utilizada pelos psicoterapeutas entrevistados e as subjetivas experiências de manejo emocional.

\section{RESULTADOS E DISCUSSÃO}

Pensar a questão do equilíbrio e do desequilíbrio emocional por parte dos psicoterapeutas remete a uma discussão sobre as competências pessoais e profissionais de psicólogos clínicos quanto à sua regulação emocional em situações intensas. Para Reis et al. (2016, p.2), "A regulação emocional compreende o manejo emocional com vista a um funcionamento social efetivo. Envolve iniciar, manter, modular ou alterar as ocorrências, intensidade ou duração dos estados internos e reações fisiológicas relacionadas à emoção". Quando as falas dos pacientes retratam o sofrimento de forma muito intensa, isso pode representar a atividade que confronta o psicólogo clínico em seu lado profissional, afetando-o emocionalmente. Ter essa capacidade de separar o que é do psicoterapeuta e o que é do outro pode ser uma tarefa desafiadora. "Quando ocorre uma emoção intensa, o ser humano pode vir a ter uma modificação em sua expressão facial, na condutibilidade cutânea, na frequência cardíaca e respiratória" (Pinto, 2005, p.184). De acordo com os participantes da pesquisa "[...] esta questão do controle é muito importante para a gente não misturar os papéis dentro da terapia" (Alamanda) e que "[...] é saber diferenciar o que é emoções do psicólogo e o que é do outro" (Violeteira). Reis et al.. (2016, p.2) abordam que "A capacidade de RE é uma habilidade importante para uma vida socioemocional saudável". Considerando, ainda conforme esse autor, se autorregular emocionalmente aumenta a probabilidade de uma vida social adaptada.

Para neutralizar esse sofrimento, há estratégias de enfrentamento pessoal por parte dos psicólogos, como ilustra a citação dos participantes deste estudo: "[...] Então, eu procuro me trabalhar aqui dentro do consultório, é aqui, o meu espaço. [...] Eu gosto de chegar um pouco antes, daí, para eu me equilibrar 
mesmo com o ambiente, enfrentar as coisas com o local. [...] Eu fui aprendendo a não levar estas situações pra casa. Então, claro, tem dia que a terapia foi um sucesso, mas ah, eu saio com a minha energia lá no pé, eu saio acabada, eu saio muito cansada. Mas quando eu venho pra cá, eu fecho aquela porta e fico uns 10 a 15 minutos, aqui, pensando, fazendo alguma coisa, depois eu saio ali da porta pra fora, é a Alamanda. [...] Esta questão de questionar pensamentos, quando eu fico mexida com a sessão, eu faço respiração, relaxamento que a gente faz fechar os olhos e imaginar um lugar que a gente gosta muito e trabalhar a respiração junto, o teu corpo vai relaxando" (Alamanda). Em relação à estratégia de regulação emocional, Rodriguez e Gondim (2014, p. 7) argumentam que:

A ativação antecedente ocorre antes de a emoção ser eliciada, como forma antecipada de enfrentar a situação em vista. A ativação consequente está relacionada ao controle da emoção depois de ativada, a fim de atenuar suas consequências. Como a estratégia de regulação emocional antecedente exige uma preparação consciente do indivíduo para enfrentar a emoção, é possível afirmar que o processo seja acompanhado de uma mudança de atitude, de modo que haja uma nova reação do indivíduo diante do acontecimento e, em consequência, da experiência e expressão emocional. Por seu objetivo de intencionalmente provocar uma mudança de sentimento, a forma antecedente de regular a emoção é também chamada de regulação emocional profunda, sendo as estratégias pertencentes a esse grupo consideradas mais eficazes para preservação do bemestar.

Segundo os participantes, a atividade física serve como uma forma de estratégia pessoal para lidar com o desgaste emocional advindo do trabalho. $\mathrm{E}$ de acordo com os entrevistados: "[...] Eu tenho que ter paralelo algumas atividades físicas que me gerem uma compensação né. Eu tenho o hábito de fazer coisas que eu gosto e que me deem prazer, né, buscar momentos de relaxar com mais intensidade. [...] Você vai me ver passeando no parque, eu gosto de fazer isto porque eu entendo que isto me relaxa, me faz bem, é uma das formas que eu manejo as emoções negativas" (Dália). Segundo Silvestre e Vandenberghe (2013), pessoas psicologicamente resilientes no dia a dia utilizam as emoções positivas para regular as negativas, estratégia que, muitas vezes, se mostra eficaz.

Os participantes se apresentam como responsáveis pela sua desregulação emocional. Esse desequilíbrio emocional é emitido pelos psicoterapeutas a partir da relação que têm com as suas experiências de trabalho na clínica. "A desregulação emocional pode incitá-lo a queixar-se, provocar e atacar ou afastar-se dos outros. Ele pode ficar ruminando sobre suas emoções, tentando descobrir o que está acontecendo" (Leahy et al., 2013, p. 20).

Os relatos dos participantes da entrevista retrataram essa questão: "[...] $E$ quando ele chegou e disse isto, eu realmente me impactei, foi muito pesado pra mim, foi muito, muito pesado pra mim. (Olhos lacrimejados). Eu digo Bah, que 
sapatada da vida que ele levou, né, foi muito pesado para mim. E eu me emocionei no momento em que estávamos ali. E pensei, ele esta precisando de mim mais do que eu em si, de mim mesmo. [...] Eu não chorei, não, naquele momento eu não podia, mas ai eu cheguei em casa, e daí, eu realmente, foi uma noite em que eu perdi o sono. [...] Eu fiquei pensando, né, eu não parei para identificar que foi. O que nele fez, que mexesse tanto comigo, questões pessoais. Eu pude me identificar: Isto poderia ter acontecido comigo?. [...] Eu me assustei, me entristeci, fiquei com medo. E naquele momento eu percebi que tem alguém precisando de mim. Esta situação me marcou, acho que vou lembrar para o resto da vida" (Dália). Outro participante menciona que: "[...] Era uma paciente adulta, ela estava contando de uma perda. Na verdade, eu acabei me sensibilizando muito, porque eu sou mãe, e acabei me colocando no lugar dela. [...] E eu me imaginei neste lugar, eu com a minha filha. [...] E eu como mãe, acabei sentindo a mesma dor, com certeza, ela sentiu muito mais, mas senti uma gota do que ela sentiu, assim, foi muito forte. E foi uma sensação assim, de perda mesmo, assim, de tristeza em ver ela passar por uma situação assim, que ninguém gostaria de passar" (Amarílis). Conforme James (2008), é impressionante como alguns elementos podem evidenciar esses aspectos de sensibilidade.

Essa sensibilidade pode ser vista como uma habilidade essencial para os psicólogos clínicos no exercício da profissão. Essa habilidade possibilita auxiliar nos atendimentos psicoterapêuticos tanto na escuta, quanto na compreensão. Tal ato contribui para remover da sociedade os tabus que delineiam que os psicólogos clínicos não devem demonstrar suas emoções, sua sensibilidade. Para a sociedade, os psicólogos devem ser profissionais neutros, sendo que os psicólogos que demonstram suas emoções não são vistos como bons profissionais. A sensibilidade é a capacidade de captar informações ocultas nos variados momentos da vida de uma pessoa (Faleiros, 2004). James (2008, p. 3) argumenta a respeito dessa sensibilidade:

A nossa capacidade cúbica inteira é sensivelmente viva e cada pedaço contribui com suas pulsações sensitivas, leves ou agudas, agradáveis, dolorosas ou dúbias, para esse sentido de personalidade que todos, invariavelmente, carregam em si.

A perda de controle emocional envolve, em alguns casos, questões de personalidade e outras vezes de limitações, como ilustra a seguir uma das participantes. "[...] Teve uma situação especifica que eu precisei controlar e eu não consegui. Eu precisei sair do atendimento. Era um atendimento com uma criança de 6 anos, a criança tinha sido agredida. [...] A gente conseguiu criar um vínculo de atendimento e conseguimos ver as marcas. E foi um momento que eu me desestruturei, foi quando ele estava todo marcado, assim, em alto relevo. Eu não consegui. Em 7 anos foi a única vez que eu me levantei e sai de um atendimento. Eu não consegui lidar com aquilo. Aquela imagem foi muito forte. 
[...] Foi esta cena, assim, que percebi que a gente precisa reconhecer os nossos limites" (Bromélia).

Segundo Alexandroff (2012), as emoções são acompanhadas de reações neurovegetativas e expressivas e, também, de alterações exteriores. As reações expressivas são contagiosas e mobilizadas do comportamento do outro. $\mathrm{O}$ sujeito é dominado pela emoção e torna manifesta a sua sensibilidade. O caráter contagioso da emoção afeta os sujeitos que estão próximos de alguém em crise.

Na pesquisa realizada em campo, os relatos de experiências dos psicólogos clínicos apontam que as origens da perda de controle emocional surgem a partir da subjetividade e das experiências de vida de cada um, considerando o perfil do psicoterapeuta. Alguns profissionais demonstram ter uma personalidade mais sensível do que outros. A desregulação emocional depende de todo o contexto em que os psicólogos clínicos estão inseridos, pois os relatos de histórias que os pacientes trazem em psicoterapia podem retratar intimamente a vida pessoal do psicoterapeuta, ou seja, o contexto e os relatos de histórias dos pacientes podem, igualmente, afetar emocionalmente um profissional. Nem todos os psicólogos fazem uso de alguma técnica específica para obter autocontrole emocional. Uma das entrevistadas menciona que: "[...] Eu, pessoalmente, não preciso utilizar técnica nenhuma, não sei se em função da minha experiência e o meu perfil de pessoa".

Alguns sujeitos têm habilidades aprendidas e de personalidade para lidar com as suas emoções. Sendo assim: "[...] Vai ter uns psicoterapeutas com uma personalidade diferenciada, um perfil mais sensível" (Violeteira). Por mais que os psicólogos nem sempre identifiquem seus estados emocionais, cada um aprendeu habilidades para manejar as suas emoções. Estima-se que algumas habilidades tenham sido exercidas na sua formação. Como preceitos da Terapia Cognitivo-Comportamental, reconhecer as estratégias utilizadas pode auxiliar no manejo artificial até que ele seja absorvido e vivido de modo natural. $O$ que pode dar a sensação de não haver técnicas específicas. Para Filho e Moreira (1997), a função da educação se torna essencial na preparação para o trabalho. As habilidades requeridas pelo trabalhador são relacionadas com aquelas desenvolvidas na sua formação.

As emoções negativas e positivas podem influenciar na conduta e na postura dos psicólogos clínicos perante os relatos de histórias de seus pacientes. Isso justifica a importância de conhecer os próprios limites, conforme mencionam os entrevistados: "[...] É uma situação que eu não nego e demonstro sempre é a alegria, que é quando os pacientes vão bem. E quando tem uma vitória, eu acho que comemoro mais que eles. [...] Eu não controlo a minha alegria, eu realmente comemoro. [...] Aquilo que é positivo, eu expresso" (Dália). "A expressividade positiva assume um papel fundamental na iniciação e na regulação das interações sociais" (Franco \& Santos, 2015, p.1). Outro entrevistado reforça a ideia das emoções positivas dizendo: "[...] $O$ paciente às 
vezes teve uma situação muito boa, ah, eu fico muito feliz, eu pulo, eu abraço, eu comemoro junto com ele. [...] Eu acho que esta vivência junto com ele, o paciente é muito importante, para ele se sentir acolhido, se sentir compreendido" (Amarílis). Almeida e Sobral (2005) mencionam que em vez de reprimir emoções, o sujeito que expressa emoções positivas tende a trazer vantagens positivas para o tratamento. A expressão das emoções positivas aumenta a criatividade e torna o sujeito disposto a partilhar informações, gerando mais alternativas. "As emoções positivas contribuem para a construção da resiliência" (Silvestre e Vandenberghe, 2013, p.54).

Os relatos dos pacientes, sobretudo quando diz respeito a crianças violentadas, mexem com a estrutura do psicoterapeuta, pois são falas bastante expressivas de crianças que foram agredidas e que abalam o psicológico dos profissionais, conforme o relato de uma dos participantes: "[...] Às vezes eu ficava em determinada terapia feliz com a evolução da criança. Mas ao mesmo tempo, quando ela me relatou aquela situação de violência, eu fiquei com raiva (expressão facial de raiva). Depois que a criança sai, eu dei aquela respirada (puxando a respiração). Eu nunca cheguei de chorar, assim, mas aquela situação mexeu com o meu estado emocional" (Alamanda).

As emoções negativas não são boas de expressar, mas são necessárias. Negá-las também é uma forma de perder o controle do que elas geram em si mesmo, o sofrimento. O psicólogo clínico não pode reprimir todas as suas emoções negativas, pois pode acarretar seu adoecimento. Segundo o relato dos participantes: "[...] Eu tive problemas de saúde recentemente". [...] Eu me afastei para não prejudicar os atendimentos. "A gente não pode cobrar do ser humano, a gente precisa reconhecer os nossos limites" (Bromélia). Segundo o relato de outro participante:"[...] E a gente tem uma história de vida de cada um. Eu não consigo excluir, e se eu excluir seria desumano da minha parte com o paciente, excluir tudo isso. Eu sinto em que alguns momentos, eu preciso ter o controle aqui. E esta palavra controle, tem um peso. É interessante, porque tu pode controlar aqui, mas tem uma hora que tu tem que cair" (Dália).

Outro relato diz: "[...] Na verdade a gente tem que mostrar, a gente tem que validar o que ele está relatando né, para ele tem um peso muito grande tudo isto. E realmente a gente tem que dar esta importância, de validar este sentimento. Nenhuma história de vida que eu tenha que me controlar, ou que eu não consiga terminar o atendimento" (Amarílis). Almeida e Sobral (2005) destacam que o uso das emoções pode ser genuíno ou uma estratégia para conseguir alcançar os objetivos pretendidos.

Relatar as emoções positivas e negativas para uma pessoa, o ato de compartilhá-las podem trazer benefícios para a saúde como o bem-estar físico e emocional, conforme argumenta Vandenberghe (2004, p. 40): 
Muitos conhecem o alívio proporcionado pelo fato de encontrar alguém com quem falar sobre seus sofrimentos, mesmo que esta pessoa não possa oferecer solução alguma. [...] Depois de haver relatado o que se sente, 0 insuportável se torna suportável e o inadmissível se torna admissível. Parece que no ato de relatar emoções, algo mudou.

Por meio desse estudo percebe-se que os psicólogos clínicos investigados buscam, por intermédio da psicoterapia a ajuda necessária para conter a dor, os sofrimentos, as angústias, os desequilíbrios emocionais e os traumas. Os relatos das psicólogas entrevistadas asseveram: "[...] Já teve uma situação, até engraçada em terapia, eu faço terapia. E teve uma sessão que eu, nossa, eu fui a prantos, chorei igual a uma criança, nunca chorei na minha vida daquele jeito. Eu conversei com ela, assim, Oh, como eu consigo entender assim, os pacientes quando estão em terapia, porque agora estou do outro lado, né, porque agora estou como paciente. Eu estou no momento onde eu estou externalizando todas as minhas emoções pra ti" (Amarílis). Em outra entrevista, a participante relatou que: "[...] Eu procuro trabalhar com as minhas próprias emoções. Eu faço terapia, e tipo assim, eu tenho um psiquiatra" (Bromélia). "Vem daí a importância de o terapeuta ter passado pelo seu próprio processo para estar com o cliente em uma relação fluida, espontânea, sem contaminação pela sua realidade interna" (Faleiros, 2004, p.16).

Em alguns momentos os profissionais da psicologia carregam consigo mesmos as suas angústias e sofrimentos, conforme o relato de uma das participantes: "[...] A nossa profissão acho que se torna a mais bonita e mais difícil, é por justamente a gente ter que ter esta capacidade de guardar algumas coisas no bolso. E, assim, não guardar e se emburrar, mas naquele momento ali eu preciso guardar" (Bromélia). Augusto, Freitas e Mendes (2014) destacam que o sofrimento constitui um indicador de saúde, além de ser uma vivência de afetos dolorosos, é um mobilizador para as mudanças das situações que fazem sofrer.

Os psicólogos clínicos atendem diariamente pessoas com histórias muito difíceis de vida e que podem deixar o profissional muito exausto, cansado e abalado. Um dos relatos dos entrevistados menciona que: "[...] Eu passei por situações de o paciente falar e/ou trazer uma situação muito tensa, assim, e muito pesada, de eu me sensibilizar. [...] Eu tive um paciente que trouxe uma situação bem pesada, sobre sua sexualidade" (Dália). De acordo com Faleiros (2004), é fácil perceber situações de conflito nos outros quando se passou por situações semelhantes, se tiver consciência disso pode contribuir na relação com o paciente, desde que o perigo de identificação com ele não seja muito intenso e que o psicoterapeuta consiga ter controle da situação.

O psicoterapeuta deve estar preparado para reagir positivamente ante as próprias frustações, seja quando percebe a dificuldade em que se encontra ante um cliente difícil, seja quando esse cliente the 
revela aspectos negativos da própria personalidade (Faleiros, 2004, p.16).

Em alguns momentos, expressar as emoções em psicoterapia pode resultar em aspectos positivos para o tratamento dos pacientes. Segundo o relato de uma das entrevistadas: "[...] A paciente foi super acolhedora, assim, ela trouxe, que não esperava que me ver assim, o quanto eu sou humana, tanto quanto a pessoa, né" (Amarílis). Acerca da questão de o paciente perceber que o psicoterapeuta é ser humano e que em alguns momentos pode acontecer de demonstrar suas emoções, Faleiros (2004, p.16) argumenta que:

\begin{abstract}
A segurança emocional deve estar presente, já que a percepção de sua instabilidade pode dificultar o processo psicoterapêutico. O cliente acredita que o psicoterapeuta seja equilibrado, com condições de clareza, de percebê-lo sem interferências pessoais e, assim, ajuda-lo. Porém, é importante também perceber que ninguém tem condições de ser absolutamente seguro emocionalmente. Em algum momento, essas limitações do psicoterapeuta são um fator positivo, pois ajudam o cliente a construir uma imagem mais real das próprias exigências e, ao mesmo tempo, vislumbrar o mundo de maneira não tão "perfeccionista e acabada".
\end{abstract}

Por mais que esses relatos dos pacientes sejam intensos, pesados e dolorosos, em muitos casos relatos de histórias semelhantes com a dos psicoterapeutas, cabe ao psicólogo neutralizar as suas dores e saber tratá-las em outro ambiente, que não seja o consultório. Para Faleiros (2004), o psicoterapeuta precisa ter conhecimento de seus problemas, evitando danos ao paciente para que haja um bom desempenho psicoterapêtico. Tendo em vista que o psicólogo é um ser humano como qualquer pessoa e que em algum momento pode acontecer de demonstrar o seu lado humano para um paciente, como destaca um dos entrevistados: "[...] Eu entendo que somos humanos e não uma máquina" (Dália). Faz-se necessária a maturidade das emoções no que implica ter consciência da própria capacidade emocional e afetiva, reconhecer as limitações e lidar conscientemente com os próprios afetos emoções sem ultrapassar os limites dos laços afetivos (Faleiros, 2004).

Portanto, o papel dos psicoterapeutas é ter as habilidades de serem espontâneos e flexíveis ao mesmo tempo. Espontaneidade se manifesta na participação do psicólogo clínico em ser capaz de sorrir, sentir, demonstrar entusiasmo ou cansaço mesmo no seu ambiente trabalho; e a flexibilidade se expressa em escutar, perceber, sentir e transformar tudo em gesto psicoterapêutico, voltando o olhar para as necessidades do paciente (Faleiros, 2004). A partir desses princípios, é fundamental que o psicoterapeuta se apresente como pessoa real, como ser que sente e não como uma máquina. 0 psicólogo clínico é um ser humano constituído de emoções e sentimentos e, se souber se autorregular emocionalmente, pode gerar qualidade, eficiência e sucesso em seus atendimentos psicoterapêuticos. O alto nível de inteligência 
emocional dos sujeitos seria a capacidade mais importante na explicação do sucesso no trabalho (Cobêro et al. 2006).

\section{CONCLUSÃO}

O objetivo do presente estudo foi investigar as estratégias de regulação emocional de psicólogos clínicos no período em que estão em atendimentos psicoterapêuticos, bem como relatar as estratégias empregadas pelos participantes, os desafios e a desregulação emocional em situações intensas. Às análises realizadas neste estudo indicam que a entrevista desenvolvida pode descrever de forma adequada as estratégias de regulação emocional dos participantes. Os resultados ainda sugerem que o instrumento foi capaz de mapear as diferentes dimensões da autorregulação emocional, estando em consonância com o referencial teórico utilizado. Evidências adicionais apontam que ele também foi sensível na discriminação de psicólogos clínicos com a questão de desregulação emocional, ou melhor, a perda de controle emocional quando se trata de identificação com a história do paciente, com casos de crianças violentadas, pacientes impacientes com os seus psicoterapeutas e com a ocorrência de dificuldade de empatia do psicoterapeuta com o paciente.

No tocante ao tipo de estratégias de regulação emocional, os resultados na presente investigação corroboraram os dados obtidos em estudos anteriores sobre essa questão de regulação emocional e desregulação emocional em situações intensas e, algumas vezes, dolorosas. O estudo mostrou que os psicólogos clínicos desta pesquisa tendem a empregar estratégias de regulação emocional no período em que estão em seus consultórios clínicos particulares, e preferencialmente, sozinhos.

O questionamento socrático foi mencionado por alguns participantes como sendo uma estratégia de controle emocional bastante utilizada, sendo que a menos utilizada foi a estratégia de respiração e de relaxamento muscular. Cabe ressaltar que o questionamento socrático foi relatado pelos participantes não somente como uma estratégia de controle emocional, mas como uma forma de reconhecer os seus limites e os pensamentos automáticos a fim de trabalhar consigo mesmo os pensamentos negativos. As estratégias de RE como seleção da situação, atenção posicionada e mudança cognitiva são importantes ferramentas de controle emocional. Os participantes demonstraram recorrer essas estratégias mesmo sem nomeá-las.

Os participantes relataram que diante de determinados atendimentos intensos, a estratégia mais frequente mencionada é de realizar atividades físicas e de momentos que gerem prazer com mais intensidade. Pelos dados obtidos, pode-se pensar que os psicólogos clínicos reconhecem as diversas emoções e são capazes de avaliar que determinadas estratégias são mais eficientes para uma emoção do que a outra. 
Um ponto que merece destaque é que todos os participantes, diante das emoções e dos sofrimentos que os incomodam, procuram por psicoterapia, buscando não somente aliviar os seus sofrimentos, mas visando reconhecer os seus problemas para poder ajudar as pessoas que os buscam.

Esse resultado sugere a necessidade de se criar programas de prevenção e intervenção, com a finalidade de promover a conscientização das diferentes emoções e o desenvolvimento de estratégias de regulação afetiva. Bem como, contribuir para elevar o sentimento de competências de psicólogos clínicos ao lidarem com os seus sentimentos e suas emoções. A realização desses programas se torna ainda mais importante à medida que não haja dúvida de que a capacidade do indivíduo de regular suas emoções está relacionada ao ajustamento psicológico.

\section{CONSIDERAÇÕES FINAIS}

No exercício profissional de psicólogos clínicos não se pode direcionar o sofrimento e o desequilíbrio emocional apenas para os pacientes, é preciso se constituir emocionalmente competente. Os profissionais precisam reconhecer os seus limites de atuação e se conhecer muito bem, reconhecendo que quando não estão bem devem procurar ajuda para melhor desempenhar suas atividades profissionais. Somente se pode ajudar ao próximo, quando se está bem consigo mesmo, identificando seus problemas e suas particularidades. Assim, é relevante saber separar a vida pessoal da profissional para não deixar as interferências externas tomar conta do sujeito e perder o equilíbrio emocional no momento em que está atendendo.

O fato de o trabalho psicoterapêutico ser guiado por princípios éticos faz com que o psicólogo clínico seja bastante exigente consigo mesmo, no que diz respeito à regulação emocional no atendimento clínico. Dessa maneira, quando um profissional perde o controle das suas emoções, acaba questionando o seu potencial e suas competências.

Assim, considera-se, neste estudo, que no caso deste grupo de psicólogos clínicos, conhecer e utilizar o repertório de estratégias de regulação emocional auxiliou de modo significativo a lidar com as demandas. Nas situações de maior conflito, existiu uma tendência a utilizar recursos empíricos em detrimento das técnicas profissionais.

Cabe dizer que também se consideram as limitações desta pesquisa, especialmente quanto ao número reduzido de participantes e ao instrumento utilizado. Sugere-se que sejam realizados novos estudos, quantitativo e qualitativo, a fim de fortalecer a compreensão de como os psicólogos clínicos gerenciam suas próprias emoções, quais são as estratégias de enfrentamento e de regulação emocional que dão suporte à atuação ou que possam contribuir efetivamente na prática. Sobretudo, sugere-se que tais investigações sejam 
realizadas com diferentes populações, realidades socioculturais e culturais. Há a necessidade de mais estudos com base nessa perspectiva voltada aos profissionais de psicologia em decorrência do desgaste físico e emocional relacionadas ao trabalho.

Quanto ao instrumento de coleta de dados desenvolvido, embora o intuito fosse conhecer as vivências e apresentar as estratégias do grupo de profissionais, vale ressaltar a importância da criação de novos instrumentos que possam validar as informações obtidas nesta coleta de dados.

Fica a expectativa de que este estudo possa iniciar uma série de novas investigações e pesquisas, para atenuar a escassez de instrumentos nacionais de regulação emocional. Embora existam avanços em instrumentos de medidas, são necessários novos estudos, pois, conforme mencionam Cruvivel e Boruchovitch (2010, p.8), "os esforços são ainda incipientes, o que torna necessária a continuidade de pesquisas para o desenvolvimento e o refinamento de medidas dessa variável em nosso meio". A construção do instrumento de pesquisa pode ajudar na avaliação, na prevenção e na intervenção com os psicólogos clínicos.

Por fim, acredita-se na necessidade de um olhar mais amplo para as emoções e experiências profissionais da psicologia. Os psicoterapeutas carregam consigo suas experiências de vida e nem sempre estão preparados para gerenciá-las. Em muitos casos, como mencionado pela voluntária da pesquisa "[...] precisamos guardar as dores no bolso para poder ajudar o próximo" (Bromélia).

\section{DECLARAÇÃO DE CONFLITOS DE INTERESSE}

Não há conflitos de interesse.

\section{REFERÊNCIAS}

American Psychological Association. (1996). APA Practice Organization, Promoting supporting practicing psychologists, occupational vulnerability for psychologists. New York, Norton: Karen Saakvitne.

Alexandroff, M. C. (2012). O papel das emoções na constituição do sujeito. Construção psicopedagógica, 20(20), 35-56. doi:10.1590/S141569542012000100005.

Almeida, F. J. R., \& Sobral, F. J. B. A. (2005). Emoções, inteligência e negociação: Um estudo empírico sobre a percepção dos gerentes portugueses, Revista de Administração Contemporânea, 9(4), 09-30. doi: 10.1590/S1415-655520050000400002. 
Augusto, M. M., Freitas, L. G., \& Mendes, A. M. (2014). Vivências de prazer e sofrimento no trabalho de profissionais de uma fundação pública de pesquisa. Psicologia em Revista, 20(1), 34-35. doi:10.5752/P-16789523.2014v20n1p34.

Bardin, L. (1977). L' analyse de contenu (L.A. Reto e A. Pinheiro, Trads.). Presses Universitaries de France: Persona.Campos, C. J. G., \& Turato, E. R. (2009). Análise de conteúdo em pesquisas que utilizam metodologia clínicoqualitativa: aplicações e perspectivas. Revista Latino-Americana, 17(2), 259-264. doi:10.1590/S0104-116920090020019.

Cavalcante, R. B., Calixto, P., \& Pinheiro, M. M. K. (2014). Análise de conteúdo: Considerações gerais, relações com a pergunta de pesquisa, possibilidades e limitações do método. Informação \& Sociedade: Estudos, 24-(1), 13-18.

Cobêro, C., Primi, R., \& Muniz, M. (2006). Inteligência emocional e desempenho no trabalho: Um estudo com MSCEIT, BRP-5 e 16PF. Paidéia, 16(35), 337348. doi: 10.1590/S0103-863×2006000300005.

Creswell, J. W. (2010). Projeto de pesquisa: Métodos qualitativo, quantitativo e misto (M. Lopes, Trad.). $3^{a}$ ed. Porto Alegre, RS: Artmed Editora.

Cruvinel, M., \& Boruchovitch, E. (2010). Regulação emocional: A construção de um instrumento e resultados iniciais. Revista em Estudo, 15(3), 537-545. doi: 10.1590/S1413-73722010000300011.

Faleiros, E. A. (2004). Aprendendo a ser psicoterapeuta. Revista Psicologia Ciência e Profissão, 24(1), 14-27. doi:10.1590/S141498932004000100003.

Filho, A. A., \& Moreira, M. C. G. B. (1997). Saúde, trabalho e formação profissional. Fiocruz, p.138. doi:10.7476/9788575412787.

Franco, M. G. S. E. C., \& Santos, N. N. (2015). Desenvolvimento da compreensão emocional. Revista Psicologia: Teoria e Pesquisa, 31(3), 339348. doi:10. 1590/0102-037722015032099339348.

Gil, A. C. (2002). Como elaborar projetos de pesquisa. São Paulo: Atlas Editora. James, W. (2008). As emoções. Revista Latino Americana de Psicopatologia Fundamental, 11(4), 669-674. doi:10.1590/S1415-47142008000400013.

Leahy, R. L., Tirch, D., \& Napolitano, L. A. (2013). Regulação emocional em psicoterapia: Um guia para o terapeuta cognitivo-comportamental. (I. Haun de Oliveira, Trad.). Porto Alegre, RS: Artmed.

Lima, M. J., \& Cerveny, C. M. O. (2012). A competência social do psicólogo: Estudo com profissionais que atuam em instituições. Revista Psicologia: Ciência e Profissão, 2(32), 284-303. doi:10.1590/S14149893201200200003.

Machado, P., Veríssimo, M., Torres, N., Peceguina, I., Santos, A. J., \& Rolão, T. (2008). Relações entre o conhecimento das emoções, as competências académicas, as competências sociais e a aceitação entre pares. Análise Psicológica, 26(3), 463-478. doi:10.1590/S0870-82312008000300008. 
Marconi, M. A., \& Lakatos, E. M. (2005). Fundamentos de metodologia científica (6a ed, p. 315). São Paulo, SP: Atlas Editora.

Mocaiber, I., Oliveira, L. Pereira, M. G., Machado-Pinheiro, W., Ventura, P. R.,

Figueira, I. V., \& Volchan, E. (2008). Neurobiologia da regulação emocional: Implicações para a terapia cognitivo-comportamental. Revista Psicologia em Estudo, 13(3), 531-538. doi:10.1590/S141373722008000300014.

Miguel, F. K. (2015). Psicologia das emoções: Uma proposta integrativa para compreender a expressão emocional. Revista Psico-usf, 20-(1), 153-162.

Miguel, F. K., \& Noronha, A. P. P. (2009). Estudo da relação da inteligência emocional e estresse no ambiente de trabalho. Avaliação Psicológica, 8(2), 219-228. doi:10.1590/S1677-04712009000200008.

Pinto, F. E. M. (2005). Introdução a psicologia da emoção. Psicologia da Educação, 21(2), 183-185. doi:10.1590/S1414-697520050000200009.

Reis, A. H., Oliveira, S. E. S., Bandeira, D. R., Andrade, N. C., Abreu, N., \& Sperb, T. M. (2016). Emotion regulation checklist (ERC): Estudos preliminares da adaptação e validação para a cultura brasileira. Temas em Psicologia, 24(1), 77-96. doi:10.9788/TP2016.1-6.

Rodriguez, S. Y. S., \& Carlotto, M. S. (2017). Predictors of burnout syndrome in psychologists. Revista Estudos de Psicologia, 34(1), 141/150. doi: $10.1590 / 1982-02752017000100014$.

Rodrigues, A. P. G., \& Gondim, S. G., (2014). Expressão e regulação emocional no contexto de trabalho: Um estudo com servidores públicos. Revista de Administração Mackenzie, 15-(2), 38-65. doi:10.1590/S167869712014002003.

Silva, P. C., \& Merlo, A. R. C. (2007). Prazer e sofrimento de psicólogos no trabalho em empresas privadas. Revista Psicologia Ciência e Profissão, 27(1) 132-147. doi:10.1590/S1414-98932007000100011.

Silvestre, R. L., \& Vandenberghe, L. (2013). Os benefícios das emoções positivas. Revista Contextos Clínicos, 6(1), 50-57. doi: $10.4013 /$ ctc.2013.61.06.

Soto, E. (2002). Comportamento organizacional: O impacto das emoções (J. Pierre Marras, Trad.). São Paulo, SP: Pioneira Thomson Learning.

Strauss, A., \& Corbin, J. (2008). Pesquisa qualitativa: Técnicas e procedimentos para o desenvolvimento de teoria fundamentada (L. Oliveira da Rosa, Trad.) $2^{\mathrm{a}}$ ed. Porto Alegre, RS: Artmed.

Vandenberghe, L. (2004). Relatar emoções transforma as emoções relatadas? Um questionamento do paradigma de pennebaker com implicações para a prevenção de transtorno de estresse pós-traumático. Revista Brasileira de Terapia Comportamental e Cognitiva, 6(1), 39-48. doi:10.1590/1517554520040000100005. 
Vinuto, J. (2014). A amostragem em bola de neve na pesquisa qualitativa: Um debate em aberto. Revista Temáticas, 22(44), 203-220. doi: 10.1590/S0103-863X1997000100005.

Wittig, A. (1981). Psicologia geral (A. Berrance, Trad.). São Paulo, SP: Mc GrawHill.

Woyciekoski, C., \& Hutz, C. S. (2008). Inteligência emocional: Teoria, pesquisa, medida, aplicações e controvérsias. Revista Psicologia: Reflexão e Crítica, 22(1), 1-11. doi:10.1590/S0102-79722009000100002.

Sobre as autoras

Marina da Silva de Matos é psicóloga pela Escola Superior de Criciúma - Esucri e pós-graduanda em Gestão Estratégica de Pessoas pela Escola Superior de Criciúma - Esucri/SC. Trabalha como psicóloga no Instituto de Educação e Acolhimento em Psicologia - InCeap na abordagem Cognitivo-

Comportamental. marina1205silva@gmail.com

Sílvia Batista Von Borowski é psicóloga e docente pela Escola Superior de Criciúma - Esucri, mestre em Psicologia Clínica pela Unisinos/RS. Trabalha como psicóloga no Instituto de Educação e Acolhimento em Psicologia - InCeap na abordagem Cognitivo-Comportamental. silviavon@esucri.com.br

M.S.M. e S.B.V.B. contribuíram para a conceitualização, investigação e visualização do artigo; S.B.V.B foi responsável pela orientação do artigo; M.S.M fez a redação inicial do artigo (rascunho) e S.B.V.B e M.S.M são os responsáveis pela redação final (revisão e edição).

As autoras não possuem financiamento da pesquisa. Agradecem aos pareceristas da revista pela leitura de versão inicial e final do texto.

Recebido em: 10/12/2017

$1^{\text {a }}$ revisão em: $14 / 03 / 2108$ Aceito em: 09/07/2018 